\title{
Os egressos da UEPG e o ensino de história: a formação de professores
}

\author{
Silvana Maura Batista de Carvalho ${ }^{1}$
}

\section{RESUMO}

O trabalho realizado pretendeu avaliar e contribuir para a formação de professores, buscou atingir os objetivos propostos de oferecer subsídios para o curso de licenciatura em História da Universidade Estadual de Ponta Grossa, em especial, à disciplina de Metodologia e Prática de Ensino, extraídos da prática pedagógica do professor. Para isso reportou-se aos egressos do curso, formados no período de 1987-92, a fim de que através da análise de alguns aspectos de sua prática fosse possível estabelecer o perfil do professor formado pela UEPG.

Os professores graduados no período indicado sofreram a ação do projeto de estágio supervisionado - Marcos Referenciais da História em Ponta Grossa - implantado em 1990. Esse projeto trouxe novas dimensões ao estágio curricular que, em concordância com o Currículo Básico do Paraná, expressa uma concepção "renovada" para o ensino de História. A preocupação foi a de avaliar se e como tal concepção constitui o suporte teórico-metodológico da atuação do professor, por meio de estratégias docentes utilizadas para sua concretização.

A pesquisa possibilitou a indicação de pontos de reflexão para a avaliação do curso, e para novas políticas de formação de professores, no curso de História da UEPG. Entre eles: a necessidade de superação da desarticulação entre as disciplinas do currículo do curso; a sugestão formulada pelos professores que apontam outros aspectos, além dos já atendidos, a serem considerados na formação docente visando atender a dinamicidade da realidade atual. Esses pontos possibilitam indicar a direção a ser dada nos cursos de licenciatura - a formação do "professor reflexivo."

Palavras-chave: licenciatura, formação de professores, ensino de História, currículo

${ }^{1}$ Mestre em Educação - área de concentração: Metodologia de Ensino - UNICENTRo/unicAmP; professora assistente na área de Metodologia e Prática de Ensino de História - UEPG.

Olhar de professor, Ponta Grossa, 1(1):29-44, out. 1998. 
O trabalho realizado pretendeu avaliar e contribuir para a formação de professores, oferecendo subsídios para o curso de licenciatura em História da Universidade Estadual de Ponta Grossa - UEPG, em especial, à disciplina de Metodologia e Prática de Ensino, extraídos da prática pedagógica do professor. Para isso reportou-se aos egressos do curso a fim de que pela análise de alguns aspectos de sua prática fosse possível estabelecer o perfil do professor formado pela UEPG.

Como professora no curso de licenciatura em História na UEPG, ao trabalhar com a disciplina de Metodologia e Prática de Ensino, percebi dificuldades com relação à formação e prática pedagógica. Com a finalidade de detectar as possíveis falhas na formação inicial desses professores, decidi buscar na prática pedagógica dos egressos, graduados no período de 1987-1992, as dificuldades sentidas por eles na graduação, assim como também no cotidiano escolar, para avaliar o processo e contribuir para a formação de novos professores a serem graduados pela UEPG.

Atuando na graduação, percebi nos acadêmicos as dificuldades quanto à transposição didática dos conteúdos para o ensino. A formação da área proporciona a eles o aprofundamento em conteúdos específicos, numa visão crítica, coerente com as concepções historiográficas recentes, mas nota-se que lhes falta um suporte teórico quanto à produção do conheci- mento histórico, para que esse mesmo mecanismo seja aplicado em nível do ensino.

Na possibilidade dos egressos da UEPG falarem sobre a experiência vivida reside a riqueza da opção metodológica desta pesquisa, pois, resgatar na memória coletiva dos professores a reconstituição de sua trajetória profissional significa recuperar os diferentes sentidos e significados que esses professores, como sujeitos de sua ação, dão às suas experiências.

Conhecendo esses sujeitos, caracterizo a amostragem desta pesquisa e, inicialmente, justifico a escolha do período de 1987-92 para análise do curso de História, por ser o momento marcado por mudanças no Brasil, entre as quais a abertura política e a retomada do discurso e do processo de democratização da sociedade brasileira. Processo esse que veio permitir aos teóricos da Educação e aos educadores, calados pela força da censura no período da ditadura militar, divulgar suas idéias transformadoras e empreender nova luta por melhores condições para a Educação.

Justamente em função dessas mudanças conjunturais, vieram à tona as novas possibilidades para o sistema educacional, em especial para o ensino de História, cuja área havia sido descaracterizada, durante o regime militar, pela junção das disciplinas de História e Geografia, na criação da disciplina de Estudos Sociais.

Vindo ao encontro dessas novas possibilidades foi elaborado um novo 
projeto de estágio supervisionado para os licenciandos em História, na UEPG - "Marcos Referenciais da História em Ponta Grossa", o qual foi aplicado como projeto piloto nos anos de 1990 a 1992, sendo essa a principal razão de se ter escolhido tal período para avaliação do curso de História da UEPG.

Para viabilizar a investigação, analisei o currículo do curso de graduação em História e do ementário das disciplinas que, especificamente, trabalham com a produção do conhecimento histórico e com a formação pedagógica do futuro professor, considerando que essa análise me forneceria subsídios para traçar o perfil do professor que se pretendia formar. Nesse sentido, analisei também o "Currículo Básico para as Escolas Públicas do Estado do Paraná”, proposta essa que dá um direcionamento ao trabalho pedagógico. Em seguida, procedi à coleta de informações junto aos professores atuantes nas redes pública e particular de Ensino Fundamental e Médio.

Atendendo ao ponto central de minha preocupação, avaliar a ação das disciplinas de ensino na formação desses professores, encaminhei nesse sentido os questionamentos, assim como também solicitei as possíveis sugestões que tais professores poderiam oferecer a partir de sua experiência enquanto acadêmicos e como docentes.

Convém salientar que o recorte feito às disciplinas que subsidiam o su- porte teórico-metodológico do professor de História constituiu a minha opção como educadora e pesquisadora.

Assim, ressalto também a importância do encaminhamento metodológico dado à análise e interpretação dos depoimentos de tais professores que, a partir de sua experiência como acadêmicos e de sua prática docente, revelam dados riquíssimos da memória de sua trajetória profissional, sendo essa memória construída coletivamente num dado momento e contexto histórico. Isto possibilitou-me fazer o imbricamento entre Memória e História e assim, como historiadora, estar atenta ao valor histórico da memória desses professores, mesmo que percebida na coletividade e não na singularidade de cada um deles.

Com essa finalidade é que realizei a pesquisa ora relatada, que visou a buscar, na prática dos egressos da UEPG, alguns aspectos básicos de sua formação inicial, como: a avaliação das disciplinas ofertadas no curso de licenciatura em História, e a identificação das concepções historiográficas e pedagógicas assumidas a partir de sua formação acadêmica. A pesquisa objetivou, também, identificar as dificuldades encontradas na prática pedagógica desses professores, quanto a aplicabilidade do Currículo Básico do Paraná, os encaminhamentos metodológicos dados ao ensino de História, assim como, em especial, a avaliação das disciplinas de ensino e da proposta de estágio supervisionado experienciada por eles enquanto 
acadêmicos e, ainda, suas sugestões para a melhoria dessas disciplinas.

O momento histórico parece ser propício às reformulações nos cursos de licenciatura, para atender ao novo papel do professor e da escola, pois o próprio suporte científico sofre alterações. O paradigma do conhecimento técnico-científico moderno, estruturado na base relacional da dominação e exploração, na manutenção da divisão de classes, no acesso de poucos ao saber e de muitos ao fazer, que constituiu-se até então o fator determinante das relações sociais da modernidade, não dá mais conta da realidade atual, por isso vive-se uma época de mudanças de paradigmas.

$\mathrm{Na}$ mudança paradigmática do conhecimento e da lógica, na readequação das forças produtivas do próprio sistema, é que estão as possibilidades para reversão do mesmo, talvez para um novo modelo de educação, um novo sistema político-econômico-social, gestado nos espaços contraditórios (entre os quais, o espaço do sistema escolar) gerados pelo próprio sistema capitalista, em sua versão neoliberal.

Portanto, investir na formação do profissional da educação é indiscutível para possibilitar a concretização de idéias capazes de proporcionar à educação condições reais de minar o sistema, de investir no despertar da consciência das novas gerações, de promover uma educação capaz de contribuir para as transformações sociais que encaminhem o homem para a "Humanização".

Novos elementos epistemológicos, vindos de outros saberes que não só o técnico-científico, integram essa nova visão paradigmática do conhecimento. A sua fundamentação encontra-se no mundo do trabalho, que anteriormente já consagrou muitas formas de aprendizagem, ou de aquisição do conhecimento, e que mais recentemente introduz o "debate da qualidade total", nascido das interações no chão da fábrica. Essas novas formas de aprendizagem apontam para soluções de problemas e construção de saberes que fogem dos padrões científicos preestabelecidos e vêm pôr em evidência os limites desse modo de conhecer tradicional.

Tais inovações científicas trazem condições para muitas mudanças não só no mundo do trabalho ou nas reformas educacionais que pretendam atrelar a educação ao sistema capitalista, mas ao efetivo trabalho docente, como afirmaram os professores nesta pesquisa, sugerindo a utilização de outros recursos em sala de aula: trabalho com teatro, novas metodologias e técnicas para lidar com os alunos.

Dessa forma, a ação pedagógica, até então limitada pela mera transmissão/recepção do conhecimento acumulado, vem a ser substituída por novas orientações, e assim, as licenciaturas poderão possam oferecer aos acadêmicos cursos opcionais que privilegiem o uso de técnicas de comunicação, visando à formação de um 
professor com novo perfil profissional. Professor esse, preparado para atuar em novos campos de trabalho, para em sua ação pedagógica dialogar com as diferentes realidades sociais, para fazer a mediação entre o conhecimento acumulado e a experiência vivida do aluno, possibilitando a passagem deste do estágio de síncrese em que se encontra no início do processo educativo, para o de síntese. Isso proporcionará ao aluno condições de autonomia, de início do processo de construção do próprio conhecimento, pelo mecanismo apreendido, que se tornará uma constante em sua vida.

Nesse contexto de mudanças, em superação aos modelos tradicionais de profissional e aos paradigmas da racionalidade técnica vigentes, coloca-se para o profisssional da educação um novo modelo, que considera a inserção do aspecto psicopedagógico no processo educativo, na relação ensino-aprendizagem, e no despertar para a valorização do saber da experiência docente, pois tem-se a consciência de que o professor, através da reflexão, reelabora os saberes iniciais que fundamentam a sua prática pedagógica. Os docentes participantes desta pesquisa apontam para a necessidade da pluralidade de saberes, quando apresentam as sugestões sobre a utilização de formas de comunicação e recursos para serem aplicados tanto na formação do professor através das disciplinas de ensino, quanto na prática pedagógica do Ensino fundamen- tal e Médio.

Essa pluralidade de saberes constitui o saber docente e integra a identidade profissional do professor-reflexivo, que "[...] reflete a apropriação de saberes curriculares e disciplinares, de saberes de formação, de saberes de experiência profissional e de vida, de senso comum, ou seja, de saberes sociais múltiplos" (THERRIEN apud WERNER, 1996, p. 59)

Para o professor exercer o fazer, que é o aspecto social da sua prática docente, ele precisa estar em permanente formação. Portanto o professor é "um sujeito epistêmico em ação" (KOSIK, apud WERNER, 1996, p. 59). Isto é, um sujeito histórico contextualizado, participante da comunidade em que está inserido, informado, comprometido ético-politicamente com a educação e a sociedade, e portanto competente pelas próprias experiências sociais vividas.

A construção da cultura da ação docente é a direção a ser dada à formação dos professores, que como atores sociais são imprescindíveis na sociedade sufocada por (des)valores, entre os quais podem ser citados o individualismo, egoísmo, hedonismo e o consumismo. A mentalidade atual, norteada pelos valores indicados, coloca em apatia e desinteresse as novas gerações, que atribuem a culpa da situação atual às gerações anteriores. Estas, por sua vez, encontram-se desgastadas e decepcionadas com a mentalidade e os valores modernos "do trabalho, ciência e progresso", 
que não foram capazes de cumprir a promessa de realização e felicidade humana.

Nesse contexto social cabe aos professores-educadores resgatar valores humanos como: vida, convivência, solidariedade, participação colaboração, partilha, fraternidade, entre outros. Assim, será possível construir a "cultura da solidariedade e cidadania".

No resgate das relações sociais, interpessoais e da capacidade de reflexão, poder-se-á conjuntamente construir o conhecimento necessário, possibilitador do surgimento de uma nova sociedade, assim como, atingir os objetivos ideais colocados para a "Educação Institucionalizada" que, mesmo condicionada aos interesses político-econômicos da sociedade capitalista atual, tem potencial para contribuir na transformação desta.

A finalidade da reflexão sobre a situação atual da Educação é o despertar para a necessidade de um novo modelo de profissional para a educação - "professor reflexivo". É necessário resgatar o papel social do professor como "profissional da educação", dando-lhe condições e autonomia para assumir a tarefa e a responsabilidade de desenvolver em seus alunos o raciocínio crítico; o compromisso com um currículo e ensino voltados para a realidade social; o desafio do desconhecido; o empenho na resolução de problemas; e os erros e acertos como dados importantes para uma avaliação formativa.
A postura desse profissional diante das diversas situações é a de definir problemas e tentar resolvê-los, o que lhe exigirá criatividade e atenção continuada nos processos de investigação.

A formação desse novo profissional da Educação vai muito além de conteúdos específicos e pedagógicos, na maioria das vezes ainda vistos de uma forma desarticulada nos cursos de licenciaturas ou de capacitação. Fato comprovado pelo posicionamento dos professores participantes desta pesquisa que, em unanimidade, atribuíram relevância às disciplinas de conteúdo específico em sua formação; secundarizaram as de conteúdo de Educação pela desarticulação com as demais e falta de direcionamento da reflexão para a área de interesse; e quanto as disciplinas de Ensino, ao mesmo tempo em que as valorizaram em sua formação, fizeram sugestões para a melhoria das mesmas. Ainda, apontaram para a necessidade de haver a interdisciplinaridade no curso de licenciatura, para que se tenha objetivos comuns quanto à formação, garantindo-se assim, através de uma mesma linha de formação, um suporte teórico-metodológico mais sólido aos futuros professores.

É necessário que o novo professor perceba-se situado no mundo, ou seja, contextualizado pessoal, social e historicamente, e que tenha a pesquisa como um constante questionamento.

Se o curso de licenciatura permi- 
tir ao aluno entender essas questões, o docente terá condições de superar em sua prática as dificuldades encontradas quanto às deficiências de conteúdo da área, à aplicação do currículo, ao encaminhamento metodológico da disciplina, ao desinteresse dos alunos, à tradução pedagógica dos conteúdos, à falta de material audiovisual, de livros atualizados com textos críticos.

Tendo essa nova compreensão, o professor-investigador terá condições de superar as dicotomias ensino $\mathrm{x}$ pesquisa, pesquisa $\mathrm{x}$ docência e teoria $\mathrm{x}$ prática, no exercício da pesquisa assumido como atitude cotidiana, pela leitura da realidade política-econômica e sua relação com o passado histórico, pois é no questionamento da realidade e da sua prática que poderá, através da reconstrução desta última com competência, contribuir para a transformação da realidade. A competência vem da criticidade e criatividade exercitadas, para que se possa, além de fazer, saber fazer e refazer permanentemente as relações do homem com a natureza.

Como integrante da comunidade científica, o professor faz o desdobramento do saber elaborado, a transformação do produto da pesquisa científica para o nível educacional, promovendo assim a (re)construção do conhecimento, ou seja, a produção do conhecimento ou saber escolar.

Direcionando a reflexão para o professor de História, quanto ao último aspecto mencionado, traço o per- fil, de acordo com MARSON, do professor-historiador, como aquele em cujo papel há o encontro do historiador com o professor, pois, enquanto o historiador reconstrói o objeto no passado, o professor o transforma num produto educacional. Por isso, as regras de procedimentos, os critérios e atitudes de interpretação do objeto de pesquisa e estudo são os mesmos, tanto para entender, como para ensinar História. Daí a necessidade desse professor-historiador rever sua atividade pedagógica, percebendo-se como parte integrante do processo histórico, compreendendo as limitações de seu trabalho, buscando uma transformação na prática, por meio da superação dos limites imediatos à sua ação e na redescoberta da formação de novas gerações.

A reflexão relativa às mudanças possíveis para a educação e, conseqüentemente, para a sociedade lhe trará a percepção da necessidade de construção de um projeto, sem receitas prévias. Essa construção requer a elaboração clara de um projeto político pessoal, articulado com o projeto político pedagógico escolar, ambos construídos na coletividade.

Portanto, na qualidade da formação acadêmica, na constante atualização, no fortalecimento enquanto grupo para legitimação de suas práticas, está a definição do profisssionalidade do professor. Daí a necessidade do curso de licenciatura estar mais próximo do professor formado, mantendo um diálogo com os antigos alunos, 
num processo constante de avaliação, como ocorreu na pesquisa realizada, a qual buscou, junto aos egressos da UEPG, levantar alguns aspectos importantes que na sua formação inicial apresentaram deficiências para, a partir deles, repensar o curso de História.

Como a principal questão levantada diz respeito ao suporte teóricometodológico dos professores, foram constatadas algumas dificuldades encontradas por eles na prática.

Quanto à aplicação do currículo proposto pela SEED que tornou-se o Currículo Oficial do Estado do Paraná a partir de sua implementação em 1990, a maioria dos professores inquiridos, mais de 50\%, afirmaram trabalhar de acordo com essa proposta, mas nada comentam sobre o trabalho feito. Alguns manifestaram dificuldades relacionadas à denominação dada aos temas, ou à articulação da proposta do currículo com os conhecimentos pessoais. Outros apontaram a falta de material adequado e de apoio para concretizar a proposta da SEED-PR.

Quando questionados sobre a con- cepção de ensino de História que vêm assumindo no trabalho docente, a partir da formação acadêmica, a maioria dos professores indicou a concepção renovada ${ }^{2}$; apenas um indicou a tradicional. Os professores que assumem exclusivamente a concepção renovada explicam assumi-la por valorizarem pontos como: desenvolvimento da consciência crítica; favorecimento do raciocínio histórico; possibilidade de os alunos pensarem-se enquanto agentes históricos; formação acadêmica recebida numa concepção de História que assume um enfoque renovado, dinâmico e processual; proposta adequada; visão de totalidade; atenção às expectativas dos adolescentes; ensino atrativo, interessante, e participativo; promoção da integração do aluno ao cotidiano e à história; demonstração do valor da história na formação para a cidadania; ênfase ao fato de a disciplina História precisar corresponder à dinâmica do homem, "ser" em constante transformação.

Assim como há profissionais que

\footnotetext{
${ }^{2}$ Entende-se por concepção renovada de História, a visão da história como processo, o homem como sujeito histórico, buscando compreender a totalidade desse processo. Têm por tácitas a respeito da História uma série de posições básicas: - busca de uma concepção global do processo histórico, em seus aspectos estruturais (econômico, social, político, mental); - adoção de uma linha problemática que questione o passado e o presente; - conceito de longa duração como visão dinâmica do tempo; - preocupação com o homem em seu aspecto social e cotidiano; abertura às demais ciências humanas e exatas; - utilização de métodos de pesquisa qualitativos e quantitativos' (TRINDADE apud LUPORINI; 1989, p.32).

A expressão Concepção Renovada para o ensino de História é utilizada neste trabalho, assim como no instrumento de pesquisa aplicado por ter sido adotada pelo grupo de metodologia do ensino de História da UEPG . Essa adoção se deu porque tal expressão está presente no Currículo Básico do Paraná, de acordo com o qual foi elaborado o projeto extensionista de estágio supervisionado em História na UEPG - "Marcos Referenciais da história em Ponta Grossa".
} 
têm consciência da concepção renovada que se coloca para o ensino de História em sua graduação, há aqueles que se colocam de forma contraditória, pois afirmam seguir a concepção renovada, mas a justificativa apresentada não corrobora seu posicionamento, pois relaciona os acontecimentos históricos com os dias atuais, mas também com causas e conseqüências.

Outros, ainda, valorizam a perspectiva da totalidade. E um professor compreende a concepção renovada e a tradicional de forma polarizada, ignorando que o novo surge do velho.

Outro aspecto abordado sobre a questão curricular diz respeito ao embasamento do ensino de História, nas escolas em que os professores pesquisados atuam. A maioria deles aponta que seu trabalho é fundamentado na proposta curricular oficial, sendo que alguns desses professores utilizam também o livro didático. Há algumas indicações de planejamento anual feito pelos professores da área, e outras de utilização de uma proposta independente.

Quanto aos conteúdos propostos no currículo, apresentados em forma de temas que seguem a linha cronológica, já comentou-se que muitos professores afirmam seguir a proposta da SEED. Um número expressivo de professores afirmam ter dificuldade em articular essa proposta com seus conhecimentos pessoais, e outros indicam a inexistência de material adequado para a concretização da proposta e a falta de bibliografia dispo- nível. Um professor afirma ter tentado, mas não ter conseguido devido a pequena carga horária destinada à disciplina.

Inquiridos sobre o trabalho com os conteúdos, a maioria assevera que os apresenta com flexibilidade e abertura para articular outros assuntos. Uma parcela representativa indica a apresentação dos conteúdos de acordo com o programa proposto, enquanto uma minoria aponta o trabalho de forma temática, ou seqüencial e narrativa. Embora demonstrem esses posicionamentos, os professores não exemplificam como isso ocorre.

Na prática dos professores de História formados na UEPG, de 1987-92, constata-se que todos têm noções sobre uma concepção renovada para o ensino de História, advindas de sua formação acadêmica e alimentadas pelas leituras e reflexões, no decorrer da construção de sua prática. Mas existem muitas lacunas na compreensão dessa concepção, evidenciadas nas respostas dadas pelos professores sobre o seu trabalho com o Currículo do Paraná, o qual carrega suas contradições.

A partir dos dois aspectos pesquisados, o projeto de sua formação inicial e a relação do professor com o Currículo Básico do Paraná, norteador de sua prática, revelou-se a necessidade de buscar na prática cotidiana desses professores uma melhor compreensão da realidade estudada.

Quanto à prática pedagógica, os professores foram questionados sobre 
vários pontos. Partindo das dificuldades encontradas inicialmente em sua carreira , a maioria dos professores apontaram como a dificuldade mais crucial a proposta curricular do Paraná e sua concretização. Em segundo lugar, apontaram os encaminhamentos metodológicos da disciplina. Ainda, a tradução pedagógica dos conteúdos, o sistema de avaliação e a questão disciplinar ocuparam lugar de destaque entre as dificuldades.

Foram citadas também outras dificuldades sentidas pelos depoentes, como: falta de coleguismo, autoritarismo da direção, falta de liberdade para inovar, aspectos burocráticos da escola, desinteresse do poder público e dos professores pela Educação, falta de material para pesquisa, a dificuldade do educando entender a importância da disciplina História, e a questão de ter que aprender a ser professor na prática.

Esses dados revelam o desconhecimento dos professores quanto à "dureza" do cotidiano da realidade escolar, tendo em vista ser reduzida a sua experiência escolar, tanto na formação acadêmica (estágio supervisionado), quanto na pratica pedagógica, pelo pouco tempo de atuação docente. Entre esses professores, a maioria tem entre quatro e sete anos de experiência de magistério, no $3^{\circ}$ e $4^{\circ}$ ciclos do Ensino Fundamental e nas três séries do Ensino Médio; alguns têm no máximo até três anos de experiência; e a minoria tem oito anos ou mais. Esse tempo demonstra a reduzida vi- vência de todos os aspectos da realidade enfrentada cotidianamente, na prática pedagógica em construção.

Portanto, os dados reveladores desta pesquisa apontam para a necessidade de favorecer aos futuros professores a compreensão quanto ao aspecto pedagógico de sua ação, baseada na articulação entre a formação específica e a aplicação do suporte teórico-historiográfico no ensino, através da tradução pedagógica dos conteúdos, que prevê os mesmos procedimentos da produção do conhecimento histórico para o saber escolar.

$\ddot{E}$ imprescindível investir na formação inicial do professor, mas sem perder de vista que a profissionalidade do professor se constrói na práxis pedagógica, na constante reflexão na ação, reflexão sobre a ação e reflexão sobre a reflexão na ação, que tem como estágio acessível para investimentos os cursos de licenciatura. Portanto, os aspectos levantados sobre os pontos a serem atingidos na formação do professor devem ser levados em consideração nas reflexões sobre a política de formação de professores, em especial na formação de professores de História na UEPG.

\section{REFERÊNCIAS BIBLIOGRÁFICAS}

1 ABUD, Katia. Currículos de História e políticas públicas: os programas de História do Brasil na escola secundária. In: BITTEN- 
COURT, Circe. (org). O saber histórico na sala de aula. São Paulo: Contexto, 1997. p.28-41.

2 ALMEIDA, Milton José de. Imagens e sons: a nova cultura oral. São Paulo: Cortez, 1994. 110 p.

3 ANDERSON, Perry et al. A trama do neoliberalismo, In: SADER, Emir; GENTILI, Pablo (org). Pós-neoliberalismo: as políticas sociais e o estado democrático. 3.ed. Rio de Janeiro: Paz e Terra, 1995. p.139.

4 ANDRÉ, M.E.D. A Etnografia e o estudo da prática escolar cotidiana. In: Etnografia da prática escolar. Campinas: Papirus, 1993. p.35-48.

5 ASSMANN, Hugo. Pedagogia da qualidade em debate. In: Revista Impulso, Piracicaba, v.7, n.16. p.8-42.

6 BERNARDET, Jean-Claude; RAMOS, Alcides F. Cinema e História do Brasil. São Paulo: Contexto, 1988. 93 p.

7 BOURDÉ, Guy; MARTIN, Hervé. As escolas históricas. Portugal: Publicações Europa-América, 1983. 220p.

8 BURKE, Peter. A escola dos Annales 1929-1989: a revolução francesa da historiografia. São Paulo: Unesp, 1991. 154p.

9 (org.). A escrita da história: novas perspectivas. São Paulo: UNESP, 1992. 354p.

10 CABRINI, Conceição. O ensino de história: revisão urgente. São Paulo: Brasiliense, 1986. 135p.
11 CAINELLI, Marlene Rosa. Precisam nossos alunos da correção de fluxo? Boletim laboratório de ensino de história. Londrina, ano 3, n.10, abr/97.

12 CARVALHO, Anna Maria Pessoa de (coord.). A formação do professor e a prática de ensino. São Paulo: Pioneira, 1988. 136p.

13 CARVALHO, Silvana Maura Batista de. O livro didático e as concepções historiográficas: o ensino de história no $1^{\circ}$ e $2^{\circ}$ graus. Ponta Grossa: UEPG, 1995. 57p.

14 CATANI, Denice Bárbara et al. (orgs). Universidade, escola e formação de professores. São Paulo, Brasiliense, 1987, 199p. Em aberto, Brasília, ano 6, n.34, p.41-46, abr/jun. $1987 .$.

15 CHESNAIS, Francois. Novo capitalismo intensifica velhas formas de exploração. Folha de São Paulo, São Paulo, 02 nov. 1997. Globalização, especial $1,04$.

16 COLL, César et al. Desenvolvimento psicológico e Educação: psicologia da educação. Porto Alegre: Artes Médicas, 1996. 456p.

17 CUNHA, Maria Isabel da. Formação continuada de professores universitários: uma experiência na perspectiva da produção do conhecimento. Educação brasileira, n.16, v.32, 
p.189-213, $1^{\circ}$ sem. 1994.

18 CURY, Jamil. Ideologia e educação brasileira: católicos e liberais. 4.ed. São Paulo: Cortez Autores Associados, 1988. $201 p$.

19 DÂNGELO, Newton. Reflexões sobre o novo currículo de História de $5^{\mathrm{a}}$ a $8^{\mathrm{a}}$ séries do Estado de Minas Gerais - 1996. Cadernos de História, Uberlândia, n.6, v.6, p.19-32, jan.95/dez. 96, p.19-32.

20 DOSSE, François. A história em migalhas: dos annales à nova história. São Paulo: Ensaio; Campinas, UNICAMP, 1992. $267 p$.

21 DEMO, Pedro. O desafio de educar pela pesquisa na educação básica. In: DEMO, Pedro. Educar pela pesquisa. Campinas: Autores Associados, 1996, p. 5-53.

22 ENGUITA, Mariano Fernández. O discurso da qualidade e a qualidade do discurso. In: SILVA, Tomaz Tadeu (org). Neoliberalismo, qualidade total e educação. Petrópolis: Vozes, 1995, p.93-10.

23 FÁVERO, Maria de Lourdes de Albuquerque. Universidade e estágio curricular: subsídios para discussão. In: Alves (org). Formação de professores: pensar e fazer. 4.ed. São Paulo: Corte:, 1996. p.53-72.

24 FENELLON, D a. Pesquisa em história: pers pectivas e abor- dagens. In: FAZENDA: Ivani. (org).Metodologia da pesquisa educacional. São Paulo: Cortez, 1989. p.117-136.

25 Diagnóstico e avaliação dos cursos de História no Brasil: documento final. Brasília: MEC, 1986, 37p.

26 _. A questão de Estudos Sociais. In: A prática de ensino de história. São Paulo: Cortez, 1986. 71p. Cadernos Cedes 10.

27 FERRETI, Celso João. As mudanças no mundo do trabalho e a qualidade da educação. In: WERNER, Market. Trabalho, qualificação e politecnia. Campinas: Papirus, 1996. p.53-70.

28 FONSECA, Selva Guimarães. Ser professor no Brasil: história oral de vida. Campinas, SP: Papirus, 1997. 230p.

29 FREIRE, Paulo. Conscientização: teoria e prática da libertação: uma introdução ao pensamento de Paulo Freire. 3.ed. São Paulo: Moraes, 1980. 102p.

30 FREITAG, Bárbara et al. O livro didático em questão. São Paulo, Cortez: Autores Associados, 1989. 159p.

31 FREITAS, Luis Carlos de. Formação do professor para o amanhã: transformação ou modernização? (Conferência proferida no Seminário "A formação do professor catarinense para o amanhã”. Florianópolis, 
jun./1991. Texto sem revisão do português)

32 Neotecnicismo e formação do educador. In: ALVES, Nilda. Formação de professores: pensar e fazer. 4.ed. São Paulo: Cortez, 1996. 103 p.

33 GADOTTI, Moacir. A questão da educação e a formação do educador: aprendendo com a minha própria história. Em aberto, Brasília, ano 6, n.34, p.2539, abr./jun., 1987.

34 HOLLY, Mary Louise. Investigando a vida profissional dos professores: diários biográficos. In: NÖVOA, Antonio. (org). Vida de professores. Portugal: Porto Editora, 1992. p.79110.

35 HUNT, Lynn . A nova história cultural. São Paulo: Martins Fontes, 1992. 317 p.

36 KRASILCHIK, Myriam. O papel da prática de ensino nos cursos de licenciatura. In: CARVALHO, Anna Maria Pessoa de (coord.). A formação do professor e a prática de ensino. São Paulo: Pioneira, 1988. p.25-28.

37 KUENZER, Acácia Zeneida. A formação do professor. UFPR (texto mimeografado).

38 LA TAILle, Yves de. Piaget, Vygotsky, Walon: teorias psicogenéticas em discussão. São Paulo: Summus, 1992.

39 LEITE, Luci Banks (FE/ Unicamp). As dimensões interacionista e construtivista em Vygotsky e Piaget [s.l:s.n] [19--].

40 LIBÂNEO, José Carlos. Democratização da escola pública: a pedagogia crítico-social dos conteúdos. 13 ed. São Paulo: Loyola, 1995. 149 p.

41 LINHARES, Celia Frazão Soares. Trabalhadores sem trabalho e seus professores: um desafio para a formação docente. In: ALVES, Nilda. Formação de professores: pensar e fazer. 4.ed. São Paulo: Cortez, 1996, p. 9-36.

42 LUPORINI, Teresa Jussara. Lugares da memória no estado do Paraná: demandas e políticas pela preservação do patrimônio cultural. Campinas: UNICAMP, 1997. $354 \mathrm{p}$.

43

. Marcos referenciais da história em Ponta Grossa. (projeto de atividade exten-sionista) Ponta Grossa: UEPG, 1992.

44 _. Pesquisando e compreendendo história: uma experiência com alunos de $8^{\mathrm{a}}$ série. São Paulo: PUC, 1989. 178p.

45 LUPORINI, Teresa Jussara; CERRI, Luís Fernando. Marcos referenciais da história em Ponta Grossa: uma nova abordagem para o ensino de história (projeto de ensino e de atividade extensionista) Ponta Grossa: UEPG, 1996.

46 MALDANER, Maridalva Bonfati. 
“A educação em contexto de construção de paradigma emergente". In: SEMINÁRIO INTERNACIONAL DE ALFABETIZAÇÃO \& EDUCAÇÃO CIENTÍFICA, 1995. Anais... [s.l:s.n] [199-]. p.310 .

47 MARINI, Thereza. Licenciatura uma revisão avaliativa e um projeto de mudança. Didática, São Paulo, 22/23, 1986/87, p.119-122.

48 MARTINS, Maria do Carmo. A construção da proposta curricular de História da CENP no período de 1986 a 1992: confrontos e conflitos. Campinas: UNICAMP, 1996, 113p.

49 MARSON, Adalberto. Reflexões sobre o procedimento histórico. In: Repensando a história. São Paulo: Marco Zero, s.d. $141 \mathrm{p}$.

50 MINISTÉRIO da Educação e do Desporto. Parâmetros curriculares nacionais: conhecimentos históricos e geográficos. ago. 1996 (versão preliminar), $81 \mathrm{p}$.

51 NADAI, Elza. O ensino de história no Brasil: trajetória e perspectivas. Revista brasileira de história, São Paulo, v.13, n.25/26, p.143-162, set.1992/ ago.1993.

52 _. O ensino de história e a "pedagogia do cidadão". In: PINSKY, Jaime (org.) $O$ ensino de história e a criação do fato. 3.ed. São Paulo: Contexto, 1991, p.23-30.

53 A prática de ensino e a universidade. In: CARVALHO, Anna Maria Pessoa de (coord.). A formação do professor e a prática de ensino. São Paulo: Pioneira, 1988, p.29-34.

54 _. Análise da prática pedagógica o ensino de história no $2^{\circ}$ grau: problemas, deformações e perspectivas. In: ENCONTRO NACIONAL DE PRÁTICA DE ENSINO V, 1993. São Paulo: FEUSP, 1983, p.261-265.

55 NAPOLITANO, Marcos. A televisão como documento. In: BITTENCOURT, Circe (org). O saber histórico na sala de aula. São Paulo: Contexto, 1997. p.149-162.

56 PARANÁ. Secretaria de Estado da Educação - Superintendência de Educação - Departamento de Ensino de $1^{\circ}$ grau. Currículo básico para a escola pública do Paraná. Curitiba: 1990.

57 PENTEADO, Heloisa Dupas de Oliveira. O papel das universidades após a formação do professor. In: CARVALHO, Anna Maria Pessoa de (coord.). A formação do professor e a prática de ensino. São Paulo: Pioneira, 1988. p.55-60.

58 PETRUCI, Maria das Graças R. 
Moreira. Avaliação de um curso de licenciatura: percepção de alunos e ex-alunos. Didática, São Paulo, 24, p.79-85, 1988.

59 RAMOS, Maria Cecília Matoso. Formação continuada do professor. In: Didática. São Paulo, v.26/27, p.83-90, 1990/91.

60 SACRISTRÁN, José Gimeno. Mudanças curriculares na Espanha, Brasil e Argentina. Pátio revista pedagógica. Ano 1, n.0, fev./abr.,1997.

61 SALIBA, Elias Thomé. Experiência e representações sociais: reflexões sobre o uso e o consumo das imagens. In: BITTENCOURT, Circe. (org) O saber histórico na sala de aula. São Paulo: Contexto, 1997. p.117-127.

62 SALVADOR, Cesar Coll. Aprendizagem escolar e construção do conhecimento. Porto Alegre: Artes Médicas, 1994.

63 SANTOS FILHO, José Camilo dos. Articulação entre os domínios da formação inicial do professor de $1^{\circ}$ e $2^{\circ}$ graus. Didática, São Paulo, 24, p.6978, 1998.

64 SAVIANI, Dermeval. Escola e democracia. 29.ed. Campinas: Editores Associados, 1995. 104p.

65 _. Pedagogia histórico-crítica: primeiras aproximações. 6.ed. Campinas: Autores Associados, 1996. 128p.
66 SEMINÁRIO Perspectivas do ensino de história. São Paulo: FEUSP, 1988. 522p.

67 SCHIMIDT, Elizabeth Silveira. Currículo, etapas de planejamento curricular e seus fundamentos. Ponta Grossa: UEPG, 1997. (texto mimeografado)

68 SCHIMIDT, Maria Auxiliadora. A formação do professor de História e o cotidiano da sala de aula. In: BITTENCOURT, Circe. (org) O saber histórico na sala de aula. São Paulo: Contexto, 1997, p.54-68.

69 SIGNORELLI, Vinícius. Currículo: um caminho que envolve responsabilidades. Pátio revista pedagógica. Ano 1, n.0 , fev./ abr., 1997, p.8-12.

70 SILVA, Ezequiel Theodoro da. O professor e o combate à alienação imposta. 3.ed., São Paulo: Cortez, 1996. 83 p.

71 TELLES, Norma Abreu. Cartografia brasilis ou: esta história mal contada. São Paulo: Loyola, 1984. 156p.

72 THERRIEN, Jacques. Trabalho e saber: a interação no contexto da pós-modernidade. In: WERNER, MARKET. (org). Trabalho, qualificação e politecnia. Campinas: Papirus, 1996, p.53-0.

73 TRINDADE, Judite Maria Barboza; SCHIMIDT, Maria Auxiliadora M. S. Formação da sociedade brasileira. Curitiba: 
UFPR., 1992. 105p.

74 UNIVERSIDADE Estadual de Ponta Grossa. Catálogo geral. Ponta Grossa: Imprensa Universitária, 1988. 276p.

75 VALLE FILHO, Moacyr Ribeiro do. O professor como produtor de conhecimento sobre o ensino. In: CARVALHO, Anna Maria Pessoa de (coord.). A formação do professor e a prática de ensino. São Paulo: Pioneira, 1988. p.61-68.

76 VASCONCELLOS, Celso dos S.

Disciplina: construção da disciplina consciente e ativa em sala de aula e na escola. São Paulo: Escolas Profissionais Salesianas, [199-]. 74p.

77 . Avaliação: concepção dialética-libertadora do processo de avaliação escolar. São Paulo: Libertad, 1994. 101p. 